\title{
Estimation of dislocation densities in cold rolled Al-Mg-Cu-Mn alloys by combination of yield strength data, EBSD and strength models
}

\author{
S.C. Wang ${ }^{1,2}$, Z. Zhu ${ }^{1} \&$ M.J. Starink ${ }^{1}$ \\ ${ }^{1}$ Materials Research Group, School of Engineering Science, The University of Southampton, SO17 1BJ, UK. \\ ${ }^{2}$ Electron Microscopy Centre, Faculty of Engineering and Science, The University of Southampton, SO17 1BJ, \\ UK.
}

\section{Summary}

Al-Mg-Cu-Mn alloys have been developed for the packaging industry, in which large cold working deformations are normally applied that can produce high dislocation densities. In this study, we present a simplified model for the yield strength contributions and apply that to obtain the dislocation densities by determining the orientation factors, which can be obtained via the crystal information of electron backscatter diffraction (EBSD). One alloy subjected to three cold rolling reductions (10\%, 40\% and $90 \%$ ) has been analysed by EBSD, and the density of dislocations are estimated using the strengthening model. This assessment suggests dislocation densities by Taylor model are roughly consistent but slightly lower than those determined by transmission electron microscopy.

Key words: Dislocation density; strength model; EBSD

Corresponding author, E-mail address: wangs@soton.ac.ukT 


\section{Introduction}

During plastic deformation of metals and alloys, dislocations tangles, cells or subgrains walls are formed, which contribute to an increase in strength. The more severe the cold working, the higher the dislocation densities and the smaller the size of dislocation cell structure or subgrains (Polmear, 1996). The density of dislocations, however, is always difficult to determine experimentally. Traditionally there are two methods: one approach is by study of X-ray line broadening. In most instances, however, it is not possible to obtain an accurate value because the diffraction broadening is caused by both strain and small crystallite size (Cheary et al., 2000). The second method is by measurement of the length of dislocations over unit volume in transmission electron microscopy (TEM). The thickness for the observation areas in TEM foils are normally less than $200 \mathrm{~nm}$, and analysis can be hampered by dislocations escaping from the thin foils, whilst some may be out of contrast due to inappropriate diffraction conditions. Thus, estimated dislocation densities via TEM are expected below the actual values.

Since the 1940s significant progress has been made in quantitatively predicting the individual strengthening effects in metallic alloy systems, with recent models for Al based alloys approaching accuracies of about 4\% (Starink and Wang, 2003; Starink and Yan, 2003). In this study, we intend to develop a model for the yield strength contributions in work hardened alloys and to obtain the density of dislocations by combining this model with strength data and microstructural data. An important element in this is the determination the orientation factors via the electron backscattered diffraction (EBSD) technique. The dislocation densities thus obtained will be compared with TEM observations of dislocations. A cold rolled Al-Mg-Cu-Mn alloy with different deformations is used. Such alloy is a very promising candidate for car body panels in the automobile industry and is used for applications in the packaging industry.

\section{Experimental methods}

The alloys were produced at Alcan, Banbury Labs, UK. The ingots (75mm in diameter) of an Al$2.9 \mathrm{wt} \% \mathrm{Mg}-0.4 \mathrm{wt} \% \mathrm{Cu}-0.25 \mathrm{wt} \% \mathrm{Mn}$ alloy were homogenised and subsequently hot rolled down to plates of $5 \mathrm{~mm}$ thickness. These plates were solution treated at $500^{\circ} \mathrm{C}$ for 20 minutes and then cold 
rolled to $10 \%, 40 \%$ and $90 \%$ reductions (using several passes). Tensile test using dog bone type specimens were performed in an Instron machine at a constant strain rate. The longitudinal (L) direction (i.e. the rolling direction) was taken as the tensile axis. The gage length and width of the specimen were 50 and $12.5 \mathrm{~mm}$, respectively according to ASTM standard.

The EBSD specimens were prepared by electro-polishing using a solution of $33 \% \mathrm{HNO}_{3}$ and $67 \%$ methanol at a temperature of $-30^{\circ} \mathrm{C}$. EBSD measurements were carried out on the LS plane (S-short transverse) in a JEOL 6500F FEG-SEM using an automated EBSD system (Channel 5, HKL, Denmark).

For TEM sample preparation, disks of $3 \mathrm{~mm}$ in diameter were punched out from slices, ground to around $0.25 \mathrm{~mm}$ in thickness and then electro-polished using a solution of $\mathrm{HNO}_{3}$ and methanol $(1: 3 \mathrm{in}$ volume). TEM foils were examined using a JEOL 3010 microscope operating at $300 \mathrm{kV}$.

\section{The strength model}

In polycrystalline materials several hardening mechanisms are present, the five relevant for $\mathrm{Al}$ alloys are listed in Table 1 (Hornbogen \& Starke, 1993). As the obstacle strengths responsible for dislocation strengthening and precipitation strengthening are of a similar magnitude, a non-linear superposition rule should be applied (Brown et al., 1971; Starink and Wang, 2003). In contrast, other contributions are much smaller than those for precipitation and dislocation hardening, and hence a linear summation for the total hardening contribution to the yield stress is appropriate (Brown et al., 1971; Hornbogen \& Starke, 1993). The yield strength should be given by (Starink \& Wang, 2003):

$$
\sigma_{y}=\Delta \sigma_{g b}+M \cdot \tau_{\text {tot }}
$$

where $\Delta \sigma_{\mathrm{gb}}$ is the stress increment due to the grain boundaries, $M$ is an orientation factor (often termed the Taylor factor) which is related to texture and the orientation of the tensile axis relative to the main axes of the worked specimen, and $\tau_{\text {tot }}$ is the critical resolved shear stress (CRSS) of the grains, which is given by:

$$
\tau_{\text {tot }}=\Delta \tau_{0}+\Delta \tau_{s s}+\left(\Delta \tau_{D}{ }^{2}+\Delta \tau_{p p t}{ }^{2}\right)^{1 / 2}
$$


The various contributions to the CRSS are defined in Table 1.

Table 1 Different hardening contributions to the CRSS of grains

\begin{tabular}{ll}
\hline Intrinsic strengthening & $\Delta \tau_{0}$ \\
Solid solution strengthening & $\Delta \tau_{s s}$ \\
Fine grain strengthening & $\Delta \sigma_{g b}$ \\
Dislocation strengthening & $\Delta \tau_{D}$ \\
Precipitation strengthening & $\Delta \tau_{p p t}$ \\
\hline
\end{tabular}

To obtain the individual CRSS, analytical expressions based on the literature are used the vollowing considerations.

The increment in CRSS due to solid solution strengthening, $\Delta \tau_{s s}$, is described by

$$
\Delta \tau_{s s}=\sum k_{j} \cdot c_{j}^{n}
$$

where $k_{\mathrm{j}}$ are the factors describing the strengthening due to the individual elements, and $c_{\mathrm{j}}$ are the concentrations of the alloying elements in solid solution. $n$ is a constant for which different values have been suggested. For example, $n=1 / 2$ by Foreman and Makin (1966), $n=1$ by Ruf $\&$ Koss (1974), and $n=2 / 3$ by Shercliff and Ashby (1990) have been applied. In attempting to maximize predictive accuracy, the optimum value of $n$ was determined by comparison with experimental data in the ASM handbook (Davis, 1993). The following expression was found to provide the best fit:

$$
\Delta \tau_{s s}=10.5 \cdot c_{C u}+5 \cdot c_{M g}
$$

where $c_{c u}$ and $c_{M g}$ are atomic percents of $\mathrm{Cu}$ and $\mathrm{Mg}$ in the $\mathrm{Al}$ rich phase (if $\mathrm{Cu}>1 \mathrm{at} \%, n=1 / 2$ ). The contributions of $\mathrm{Mn}, \mathrm{Fe}$ and $\mathrm{Si}$ to solution strengthening are much smaller than those of $\mathrm{Cu}$ and $\mathrm{Mg}$ as most of the very limited amounts of $\mathrm{Mn}, \mathrm{Fe}$ and $\mathrm{Si}$ that are present will be included in relatively coarse intermetallic phases and dispersoids. We will treat their very small contributions as part of intrinsic strength $\Delta \tau_{0}$. 
The intrinsic strength for Al binary alloys is very low, typically in the order of $10 \mathrm{MPa}$. To account for the small contributions of $\mathrm{Mn}$ and $\mathrm{Fe}, \mathrm{Si}$ impurities we will take $\Delta \tau_{0}=15 \mathrm{MPa}$ (Davis, 1993; see also Starink \& Yan, 2003).

The Hall-Petch equation is normally used to describe the stress increment due to the grain size:

$$
\Delta \sigma_{g b}=k \cdot d^{-1 / 2}
$$

where $d$ is the grain size, $k$ is a constant for a given material and is given by the following equation (Hull \& Bacon 1984):

$$
k=M \cdot\left(G \cdot b / 2 / \pi \cdot \tau^{*}\right)^{1 / 2}
$$

where $G$ is the shear modulus of $\mathrm{Al}, b$ is the Burgers vector, $\tau^{*}$ is a critical shear stress in annealed polycrystals. Grain boundary strengthening is very small, and a sufficiently accurate description is obtained by substituting $\tau^{*}$ with $\left(\Delta \tau_{0}+\Delta \tau_{\text {ss }}\right)$. Due to the very limited contribution of grain boundary strengthening, the potential influence of subgrains and elongation of grains is very limited. Hence, in this work, we will not consider the details of subgrain structure, cell structure and grain shapes that can be observed in Fig. 1.

The increment for work hardening in non-heat treatable alloys is due to the increased dislocation density (Roters et al., 2000). The relationship between the increment $\Delta \tau_{\mathrm{D}}$ and the total dislocation density $\rho$ can be written as follows:

$$
\Delta \tau_{\mathrm{D}}=\alpha \cdot G \cdot b \cdot v_{\rho}
$$

where $\alpha$ is a constant, about 0.3 (Ashby, 1970; Nord-Varhaug et al., 2000). The present alloy was not artificially aged and there is no precipitation strengthening. Therefore, the yield stress is given by:

$$
\sigma_{y}=\Delta \sigma_{g b}+M \cdot\left(\Delta \tau_{0}+\Delta \tau_{s s}+\alpha \cdot G \cdot b \cdot \sqrt{ } \rho\right)
$$

\section{Results and discussion}

The typical (sub-)grain boundary maps from EBSD analysis for three specimens cold rolled to 10, 40 and $90 \%$ reductions are presented in Fig. 1. These figures clearly show that the density of small angle grain boundaries $\left(2-12^{\circ}\right)$ increases with increasing cold work. Figs. 2 (a-c) show the $\{111\}$ pole figures with different reductions. All rolled samples exhibit typical fcc cold rolling textures which qualitatively 
appear similar. The textures consist of the continuous $\beta$ fibre textures, which runs through the copper orientation (C) $\sim\{112\}<111>$, via the $\mathrm{S}$ orientation $\sim\{123\}<634>$, to the brass orientation (B) $\{011\}<211>$. Fig. $2 d$ shows the schematic $\{111\}$ pole figure of these three different texture components.

As all the crystal orientations for individual grain are recorded in the EBSD data, it is possible to determine the Taylor factor in any tensile axis using the simplified Bishop and Hill (1951) method for $\{111\}<110>$ slip. The Taylor factors were calculated to be $2.98,3.08,3.13$ for reductions of $10 \%, 40 \%$ and $90 \%$, respectively. The measured yield stresses from tensile tests are $215^{ \pm 5}, 268^{ \pm 5}$ and $372^{ \pm 5} \mathrm{MPa}$ for reductions of $10 \%, 40 \%$ and $90 \%$, respectively. The contributions by solid solution and grain boundary strengthening can be obtained from Eq. 3a and Eq. 4. Therefore, from Eq. 7, the dislocation densities can be calculated as shown in column 3 of Table 2 .

Table 2. The estimated dislocation densities on different cold rolling reductions

\begin{tabular}{lllll}
\hline Reduction & $\sigma_{\mathrm{y}}(\mathrm{MPa})$ & $\rho\left(\mathrm{m}^{-2}\right)$ by Taylor & $\rho\left(\mathrm{m}^{-2}\right)$ by TEM & $\rho\left(\mathrm{m}^{-2}\right)$ (considering \\
& & & & 3.5 slip systems) \\
$10 \%$ & $215^{ \pm 5}$ & $2.2^{ \pm 0.2} \times 10^{14}$ & $2.2-3.3 \times 10^{14}$ & $2.9^{ \pm 0.2} \times 10^{14}$ \\
$40 \%$ & $268^{ \pm 5}$ & $4.2^{ \pm 0.3} \times 10^{14}$ & $4-6 \times 10^{14}$ & $5.0^{ \pm 0.3} \times 10^{14}$ \\
$90 \%$ & $372^{ \pm 5}$ & $10.4^{ \pm 0.4} \times 10^{14}$ & NA & $12.3^{ \pm 0.4} \times 10^{14}$ \\
\hline
\end{tabular}

To validate the dislocation densities by the present model, TEM work has been carried out. Dark-field images have been recorded for specimens of $10 \%$ and $40 \%$ reductions (Fig. 3). Since a dislocation is a line defect, this is defined as the total length of dislocation per unit volume. Equivalently, it is the number of dislocation lines intersecting a unit area. Dislocation densities were calculated by measuring number of dislocations divided by the intersecting length and the foil thickness. Several approaches to determine the thickness of TEM foils have been discussed by Williams and Carter (1996). Among them two approaches are relatively more widely used: one utilises the Kossel-Mollenstedt fringes in convergent beam electron diffraction (CBED) pattern and the second uses thickness fringes. Unfortunately, both fringes cannot be distinguished due to the lattice distortion resulting from the 
heavy plastic deformation introduced by the cold rolling. Whilst exact measurement is impossible, it is well known that transparent foils are typically between 70 and 200nm thick. From comparison with other TEM work we can estimate the thickness to be between about 100-150nm. Thus we estimate the thickness to be $125 \pm 25 \mathrm{~nm}$, and results of the dislocation density calculations are shown in column 4 of Table 2. Fig. 4 illustrates the dislocation densities with three reductions measured by TEM and estimated by Taylor model based on Bishop-Hill calculation. The dislocation densities determined by the model are somewhat lower than by TEM, which could be due to higher estimation of $M$ value in the Taylor model which requires that 5 slip systems are activated. The work by Clausen et al (1998) based on the self-consistent model by Hutchinson (Hutchinson, 1970), however, shows that 3 or 4 slip systems rather than 5 occur in fcc polycrystals such as aluminium, with a corresponding $\mathrm{M}$ of about 2.6 (Starink and Wang, 2003). Column 5 in Table 2 shows the estimated dislocation densities by taking the average of the cases where three and four systems are active. Even though the dislocation densities determined by the model are somewhat higher than by TEM, which could be due to some dislocations escaping from the foils during the foil preparation or some dislocations being out of contrast, the two determinations correspond fairly well.

For very large deformation, such as $90 \%$ cold rolling reduction in this study, however, it is impossible to measure the dislocation density in the TEM because dislocation densities are so high and lattice deformation so severe that individual dislocations are no longer distinguishable, see Fig. 3c. In contrast, with the model it is possible to derive a dislocation density that appears quite realistic (Fig. 4).

These results indicate that from the perspective of achieving accurate strength models for heavily cold worked alloys, the determination of dislocation densities will be a limiting factor for the accuracy of the model, with for very high reductions (higher than about 50\%) direct dislocation counting by TEM being near to impossible. From the perspective of using reliable strength models in conjunction with yield strength measurement and EBSD determination of $M$ factors as an indirect method for dislocation density determination, we found a good correspondence with direct dislocation density determination by TEM for medium cold rolling reductions. Thus this indirect method of determination of average dislocation density is promising and further validation experiments are planned. 
It may be argued that dislocation density can be calculated by a given average value of orientation factor (for example, 3.06 for Taylor and 2.6 for the self-consistent model) rather than through the procedure using texture measurement followed here. However, a large deviation could result. For example, in the Taylor model, some orientations such as $<001>$ have an $\mathrm{M}$ as low as 2.45 and some orientation such as $<111>$ have an $\mathrm{M}$ as high as 3.67 . Hence differences of up to $50 \%$ in dislocation density could result from (erroneously) neglecting the influence of texture. For the present rolled materials $M$ varies strongly with direction (see Fig. 5), and neglecting this variation would result in under or over estimates.

\section{Conclusions}

A simplified model for the yield strength contributions in a solution strengthened and cold worked Al alloy is applied to obtain the dislocation densities by determining the orientation factors, which can be obtained via EBSD. In the model for the yield strength, four contributions to the critical resolved shear stress of grains have been considered: the intrinsic yield strength, the solid solution contribution, the grain boundary strengthening, and the contribution due to work hardening by dislocations. The results indicate dislocation densities by Taylor model are roughly consistent but slightly lower than those determined by TEM.

\section{Acknowledgement}

The authors are grateful to Dr. H.S. Ubhi from QinetiQ, Farnborough, and Ms J. Yan at Southampton University for helpful discussions.

\section{References}

Ashby, M.F. (1970) The deformation of plastically non-homogeneous materials. Phil. Mag. 21, 399424.

Bihsop, J.F.W. \& Hill, R. (1951) A theoretical derivation of the plastic properties of a polycrystalline face-centered metal. Phil. Mag. 42, 1298-307.

Brown, L.M. \& Ham R.K., (1971) in Kelly, A., Nicholson, R.B., editors. Strengthening methods in crystals. Amsterdam, The Netherlands: Elsevier. 9. 
Cheary, R.W., Dooryhee, E., Lynch, P., Armstrong, N. \& Dligatch, S. (2000) X-ray diffraction line broadening form thermally deposited gold film. J. Appl. Cryst. 33, 1271-1283.

Clausen, B., Lorentzen, T. \& Leffers, T. (1998) Self-consistent modelling of the plastic deformation of f.c.c. polycrystals and its implications for diffraction measurements of internal stresses. Acta Mater. 46, 3087-3098.

Davis, J.R. (1993) ASM specialty Handbook: Aluminum and aluminum alloys, Davis and Associates, ASM Int., Materials Park, OH, USA, 1993.

Foreman, A.J.E. \& Makin, M.J. (1966) Dislocation movement through random arrays of obstacles. Phil. Mag. 14, 911-924.

Hornbogen, E. \& Starke JR E.A. (1993) Theory assisted design of high strength low alloy aluminium, Acta metal. Mater. 41, 1-16.

Hull, D. (1984) Introduction to dislocations. -3rd ed.. - Oxford : Pergamon, (International series on materials science and technology; v.37.

Hutchinson, J.W. (1970) Elastic-plastic behaviour of polycrystalline metals and composites. Proc. R. Soc. Lond. A. 319, 247-272.

Nord-Varhaug, K., Forbord, B., Benestad, J., Pettersen, T., Rønning, B., Bardal, A., Benum, S., Marthinsen, K. \& E. Nes, (2000) Substructure strengthening in aluminium alloys. Mater. Sci. Forum. 331-337, 1387-1392.

Polmear, I.J. (1996) Light Alloys: Metallurgy of the light metals. Third edition. New York: Halsted Press, An imprint of John Wiley \& Sons, Inc.

Roters, F, Raabe, D. \& Gottstein, G. (2000) Work hardening in heterogeneous Alloys-A microstructural approach based on three internal state variables. Acta mater. 48, 4181-4189.

Ruf, P. \& Koss, D. (1974) Solid-solution hardening of the ternary system Nb-Hf-W. Phil. Mag. 30, 1319-1326.

Shercliff, H.R. \& Ashby M.F. (1990) A process model for age hardening of aluminium alloys-I. The model. Acta Metall. Mater. 38, 1789-1802.

Starink, M.J. \& Wang, S.C. (2003) A model for the yield strength of the overaged Al- $\mathrm{Zn}-\mathrm{Mg}-\mathrm{Cu}$ alloys. Acta Mater. 51, 5131-5150.

Starink, M.J. \& Yan, J. (2003) A model for strengthening of Al-Cu-Mg alloys by S phase. Proc. 1st Int. Symp. Metall. Modeling for Al Alloys (M. Tiryakioglu and L.A. Lalli, Eds.), October 12-15, Pittsburgh, PA, USA, ASM International, Materials Park, Ohio, USA, pp. 119-126. 
Taylor, G.I. (1938) Plastic strains in metals. J. Inst. Metals. 62, 307-324.

Willams, D.B. \& Carter. C.B. (1996) Transmission electron microscopy. New York: Plenum Press.
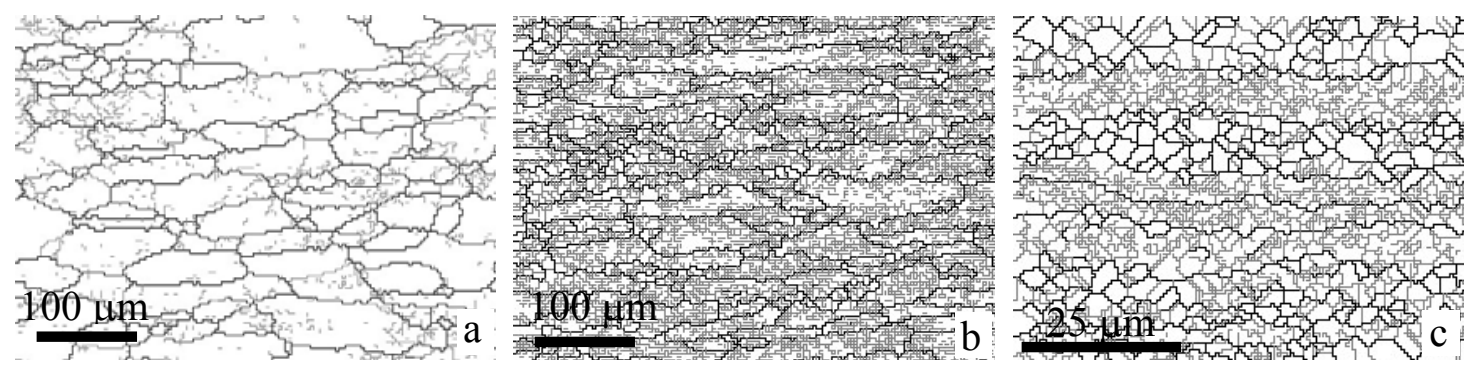

Fig. 1. Grain boundary maps of cold rolled Al-2.9wt $\% \mathrm{Mg}-0.4 \mathrm{wt} \% \mathrm{Cu}-0.25 \mathrm{wt} \% \mathrm{Mn}$ with (a) 10\% reduction; (b) 40\% reduction and (c) $90 \%$ reduction. The latter sample has been heat treated at $200^{\circ} \mathrm{C}$ for $118 \mathrm{~h}$ to obtain higher quality of EBSD map. The grey lines indicate boundaries with misorientations between $2-12^{\circ}$, and dark lines show the high angle grain boundaries $\left(>12^{\circ}\right)$. 


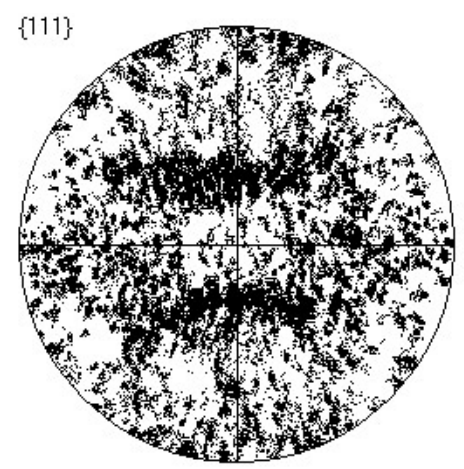

a

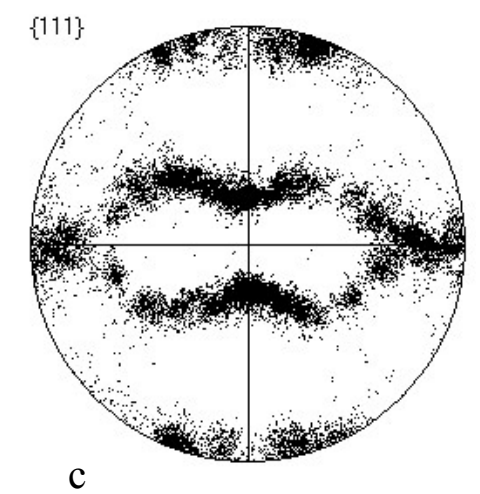

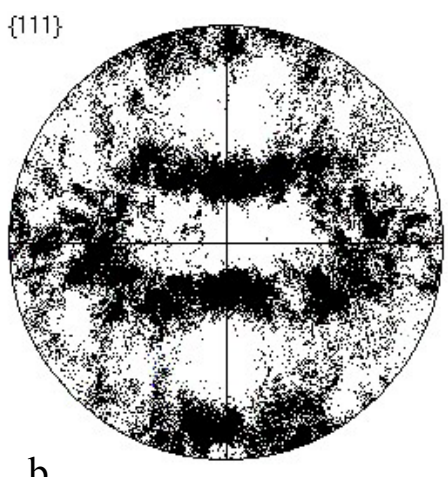

$\mathrm{b}$

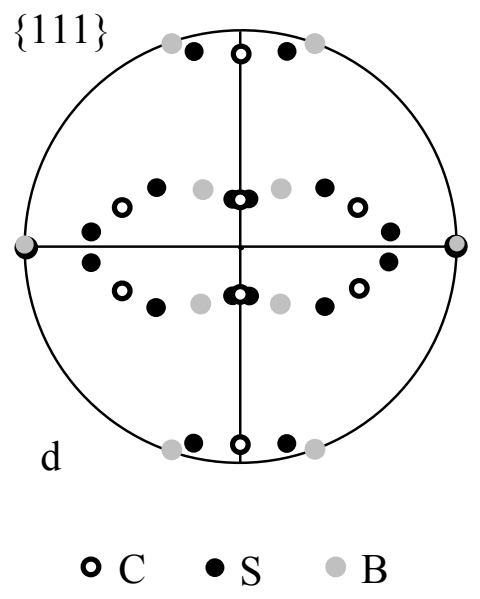

Fig. $2\{111\}$ pole figures of Al-2.9wt $\% \mathrm{Mg}-0.4 \mathrm{wt} \% \mathrm{Cu}-0.25 \mathrm{wt} \% \mathrm{Mn}$ cold rolled to (a) $10 \%$ reduction; (b) $40 \%$ reduction and (c) $90 \%$ reduction. A schematic of three texture components: Copper $\sim\{112\}<111>, \mathrm{S} \sim\{123\}<634>$ and Brass $\{011\}<211>$, is provided in (d). 

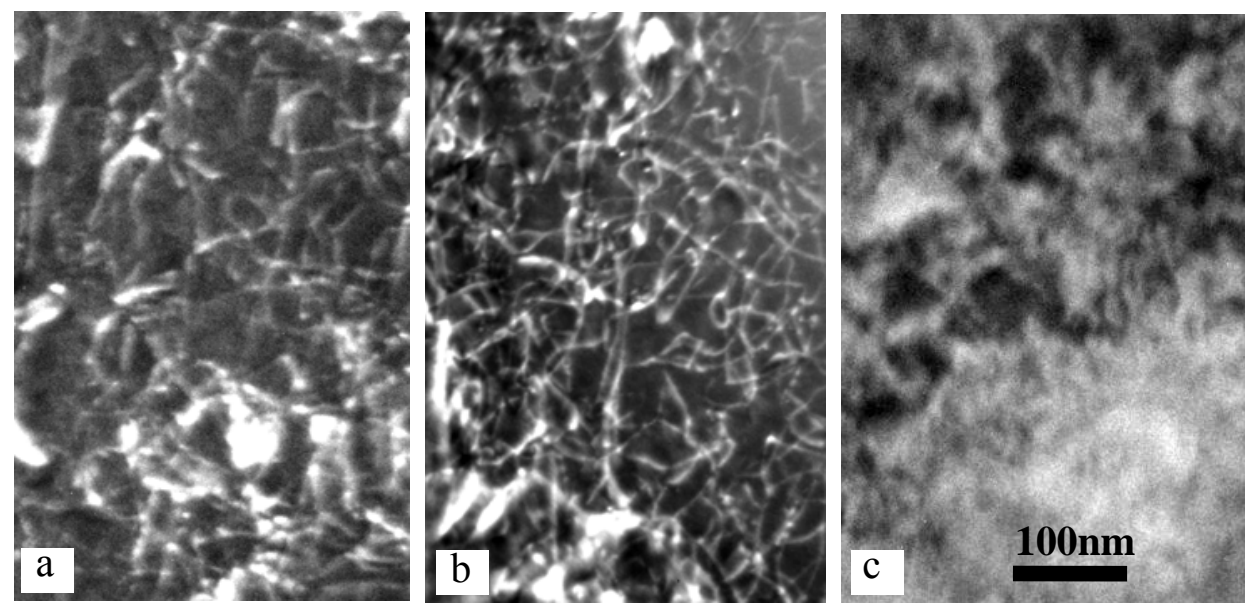

Fig. 3 Dislocation images in cold-rolled Al-2.9wt $\% \mathrm{Mg}-0.4 \mathrm{wt} \% \mathrm{Cu}-0.25 \mathrm{wt} \% \mathrm{Mn}$ alloys. (a) Dark-field image, 10\% reduction; (b) Dark-field image, $40 \%$ reduction; (c) Brightfield image, $90 \%$ reduction. 


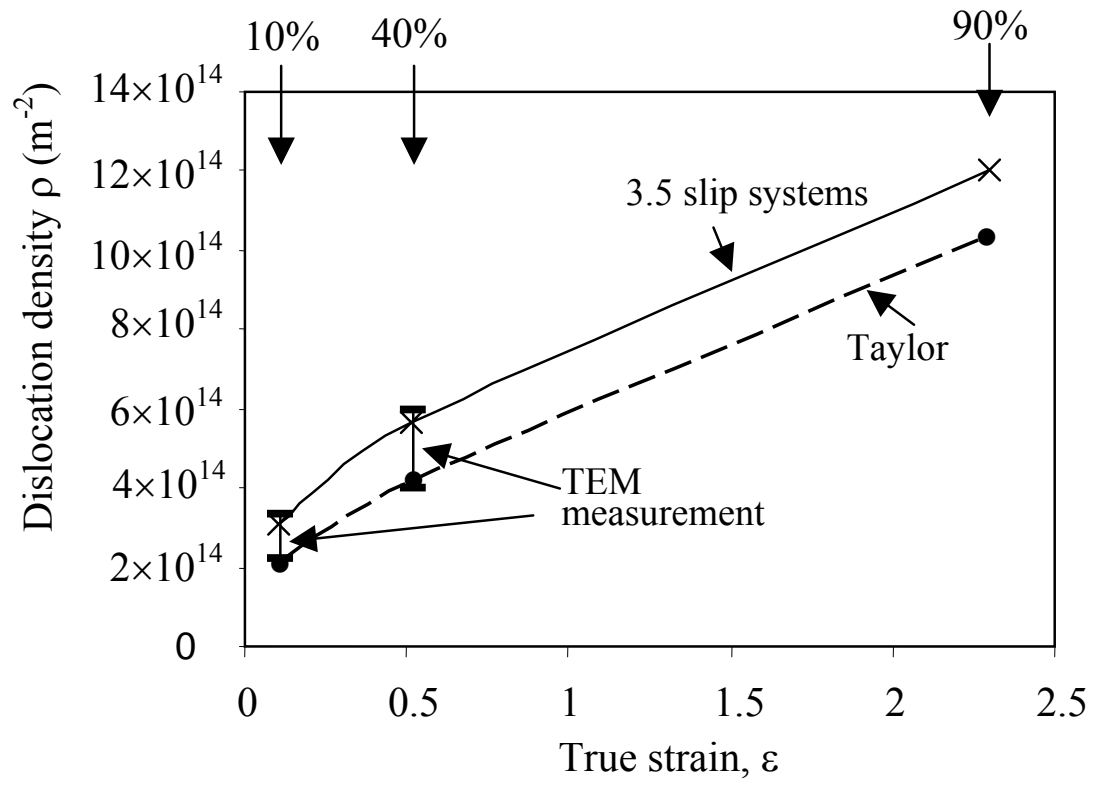

Fig. 4 The dislocation densities in Al-2.9wt $\% \mathrm{Mg}-0.4 \mathrm{wt} \% \mathrm{Cu}-0.25 \mathrm{wt} \% \mathrm{Mn}$ alloy subjected to 3 cold rolling reductions, estimated by the Taylor model ( dashed line), simplified self-consistent model (solid line) and TEM (error bars). 


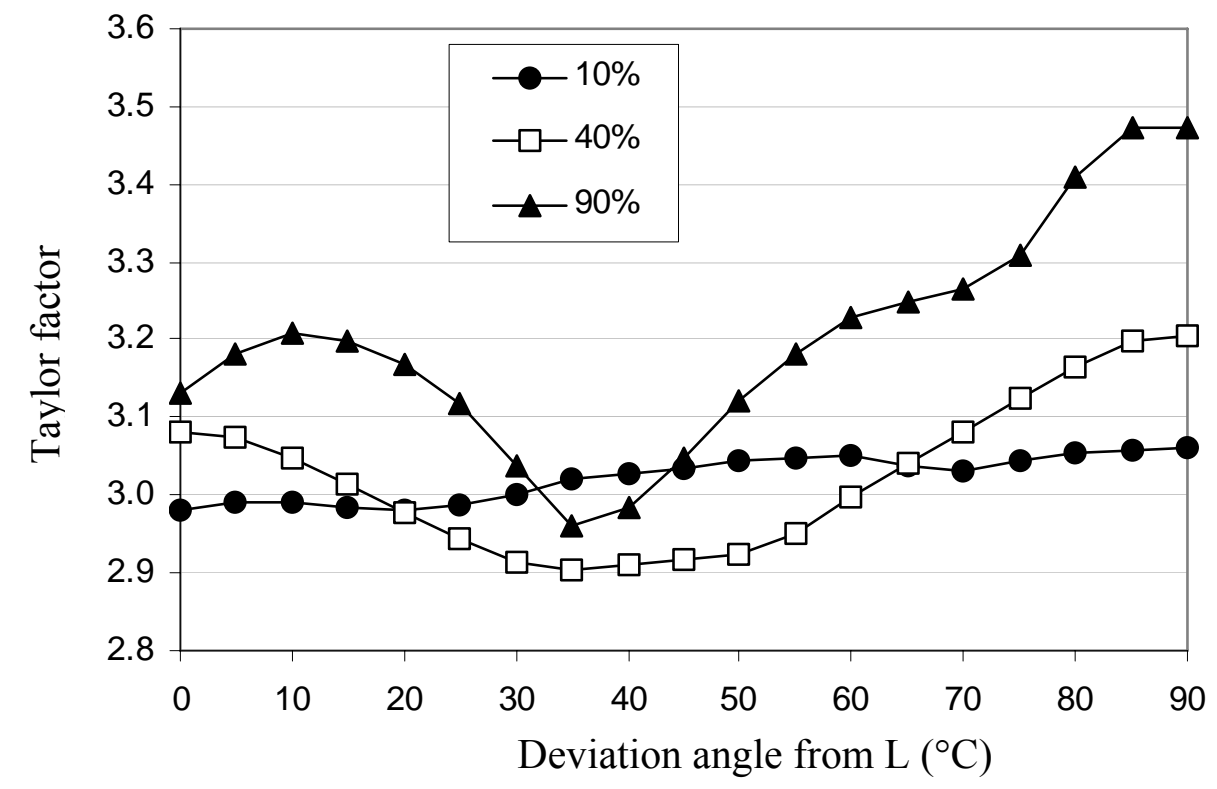

Fig. 5 The Taylor factor variation with rolling direction. 